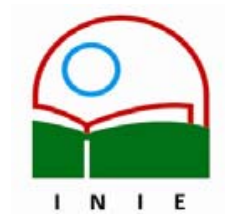

Universidad de Costa Rica

Facultad de Educación

Instituto de Investigación en Educación

ACTUALIDADES INVESTIGATIVAS EN EDUCACION

\title{
EL PRINCIPIO DE AUTONOMÍA UNIVERSITARIA ENTRE ESCILA Y CARIBDIS
}

\author{
PRINCIPLE OF UNIVERSITY AUTONOMY \\ BETWEEN ESCILA AND CARIBDIS
}

\begin{abstract}
Luis Muñoz Varela ${ }^{1}$ Juan Félix Castro Soto ${ }^{2}$

Resumen: Este artículo ofrece un registro y realiza una aproximación de análisis reflexivo, en torno a un breve conjunto de planteamientos abocados al tratamiento del tema de la autonomía en las instituciones de educación superior. El énfasis dispone la revisión de trabajos elaborados especialmente por $P$. Bourdieu y J-C Passeron, $B$. Bernstein, L. Garay, R. Barnett, y C. García Guadilla.

El propósito consiste básicamente en una revisión documental analítica y reflexiva, a partir de la cual, se pretende ofrecer un referente heurístico provisional para acercarse a la discusión y al debate que, en torno al principio de la autonomía universitaria, se encuentra actualmente en curso para ingresar a las comunidades académicas de la educación superior pública.

Palabras claves: AUTONOMÍA UNIVERSITARIA/ EDUCACIÓN SUPERIOR PÚBLICA/ TEORÍAS DE LA REPRODUCCIÓN CULTURAL/ POLÍTICAS PÚBLICAS DE EDUCACIÓN/

Abstract: This article offers a view to a group of theses that expose the higher education autonomy issue at the time that it approaches a reflexive analysis around them. There is a special emphasis in the treatment of $P$. Bordieu, J. C. Passeron, B. Bernstein, L. Garay, R. Barnett, and C. García Guadilla.

The purpose is basically to develop an analytical and reflexive bibliographical revision in order to construct a provisional heuristic referent to approach the discussion and the debate around university education autonomy, which is taking place amongst the academic communities related to public university education.
\end{abstract}

Key words: UNIVERSITY AUTONOMYI PUBLIC HIGHER EDUCATION/ CULTURAL REPRODUCTION THEORIES/ PUBLIC EDUCATION POLICIES/

\footnotetext{
1 Maestría en Ciencias con Especialidad en Investigación Educativa (Departamento de Investigaciones Educativas, Centro de Investigación y Estudios Avanzados (CINVESTAV) del Instituto Politécnico Nacional, México). Licenciatura en Filosofía de la Universidad de Costa Rica. Actualmente trabaja en la oficina de Rectoría, Universidad de Costa Rica.

Correo electrónico:Imunoz@rectoria.ucr.ac.cr.

${ }^{2}$ Psicólogo social de la Universidad de Costa Rica. Estudiante Maestría en Desarrollo Sostenible, Sede de Occidente, Universidad de Costa Rica.

Correo electrónico: ethoscr@yahoo.es
}

Artículo recibido: 19 de setiembre, 2005

Aprobado: 27 de marzo, 2006 


\section{Presentación}

Desde hace al menos tres lustros, la educación superior pública ha quedado inscrita en un contexto complejo y diverso de transformaciones estructurales. En su generalidad, tales transformaciones presentan, como uno de sus rasgos distintivos, la puesta en cuestión de los referentes de historicidad y de identidad que característicamente han constituido los cimientos que dan su definición propia a estas instituciones. Entre ellos, el principio de la autonomía es uno de los más importantes.

Los requerimientos que plantean los escenarios del nuevo presente momento histórico, definidos muy especialmente con base en los procesos y tendencias que desencadenan la globalización y la sociedad del conocimiento, pasan a establecerse en clave de una decidida reconfiguración de los espacios, sentidos y componentes del proyecto académico institucional en la educación superior. Todo ello acontece así, desde las reformas escenificadas en la dimensión de lo curricular, hasta las prácticas, sentidos y estilos de la gestión. Por tanto, a su vez, se agrega la emergencia de configuraciones académicas y espacios de gestión cada vez más acuciantes: internacionalización, redes académicas internacionales en investigación y posgrado, acreditación y evaluación, etc.

Como parte de los aspectos que definen y dan su configuración de identidad a una institución de educación superior pública, el principio de la autonomía universitaria, en la medida de que los cambios mencionados y las incidencias de la globalización y la sociedad del conocimiento, presentan una intencionalidad y una repercusión de alcance estructural, pasa a ser, asimismo, uno de los elementos fundantes que participan en la constitución de dicha identidad, ahora igualmente implicado en una situación de decidida puesta en cuestión.

Tomando en cuenta lo anterior, el propósito del presente artículo consiste en realizar un breve análisis, acerca de la naturaleza crítica que, en la actualidad, adopta el principio de la autonomía universitaria. Este propósito involucra el desarrollo de un ejercicio por avanzar elementos en procura de establecer un referente heurístico provisional, el cual permita identificar las orientaciones preliminares que, en función del análisis de las dimensiones y los aspectos de carácter diverso comprometidos en los aconteceres que intervienen y configuran la problemática actual de la autonomía en la educación superior pública, permita, en su lugar, dar una organización inicial a la reflexión y la discusión.

De este modo, en lo que a su objeto de estudio específicamente concierne, el análisis realizado se aboca a poner en perspectiva diversos acontecimientos, tendencias, nuevos escenarios y procesos emergentes que, de diferente modo y desde distintos ángulos, inciden 
y repercuten sobre el principio de la autonomía universitaria, demandándole y estableciéndole diversas presiones e inéditas dinámicas de cambio y transformación.

A tal efecto, el artículo hace acopio de algunos estudios fundamentales, y ofrece una revisión bibliográfica relativamente amplia. A propósito de esta última, se trata de investigaciones recientes realizadas durante la última década en torno a la educación superior y las problemáticas en las que esta se encuentra inscrita, como resultado tanto de las tendencias y procesos estructurales de la globalización y la sociedad del conocimiento, como por el efecto de las políticas públicas impulsadas por los gobiernos en el campo educativo.

El planteamiento del análisis en torno a la cuestión del principio de la autonomía universitaria, considera un complejo escenario poblado por muy diversos elementos, el cual se encuentra organizado en función de distintas dimensiones y niveles. Por más que pudiera dar una impresión de simplicidad y que, en su lugar, el concepto de la autonomía universitaria quisiera ser abordado, a partir de sus especificaciones más instrumentales, este principio, no obstante, está caracterizado por una gran variedad de aristas.

De momento y, de acuerdo con lo anterior, en definitiva, el ejercicio aquí realizado pretende reunir un conjunto de insumos básicos que permitan, en la medida de lo posible, prestar contribución al debate que se encuentra actualmente en los contextos de las comunidades académicas de la educación superior, y en la relación de tensión que ahora se configura entre el principio de la autonomía universitaria y los procesos y escenarios estructurales que establecen la globalización, la sociedad del conocimiento y las política pública de los últimos años en materia de educación.

\section{Referentes de incidencia estructural para la educación superior}

En 1995, la UNESCO identificó los siguientes desafíos que afronta, en general, la educación superior durante los últimos años: "a) la expansión cuantitativa; b) la diferenciación de las estructuras institucionales, de los programas y formas de estudio; y c) las restricciones financieras." (Tünnermann, 1997, p. 151).

En su lugar, la CEPAL señala que las políticas de reforma operadas en los sistemas educativos de América Latina, durante los últimos tres lustros, "han introducido profundos cambios administrativos, institucionales, pedagógicos y financieros" (CEPAL, 2000, p. 94).

Con base en el principio de la autonomía universitaria, cuatro ámbitos de problematización con incidencia significativa, pueden ser reseñados de la siguiente forma. 


\subsection{Transformaciones en la función trabajo y en los perfiles profesionales}

Durante los últimos años, las transformaciones que la globalización y la sociedad del conocimiento operan en los ámbitos de los sistemas económico/productivos, tienen repercusiones profundas sobre las estructuras del empleo y sobre la reconfiguración de los perfiles profesionales. Estas transformaciones pueden ser asociadas con la importancia radical que adoptan tanto la "apertura global", como la incorporación a los procesos productivos de las nuevas tecnologías de la información y la comunicación (TIC's). En su incidencia general, "la apertura global hace que las sociedades nacionales dependan cada vez más de su competitividad externa y ésta, a su vez, de la incorporación de inteligencia y conocimiento renovado al sistema productivo. (Hopenhayn, 2003, p. 176). Como resultado de ello, los sistemas económico/productivos acusan complejos cambios sustantivos que, entre otros factores, se presentan por la dilatación de escala y la expansión cualitativa del sector terciario de la economía.

En un enfoque anclado en el ámbito de la función laboral y de las nuevas disposiciones que la organizan, se encuentra el énfasis puesto en la máquina, como centralidad del proceso productivo, otrora disposición emblemática que daba su identidad a un sistema organizacional basado en el modelo de la cadena de montaje, para otorgar ahora un mayor grado de multifuncionalidad a los propios eslabones humanos que participan en el proceso de la producción. Este es un desplazamiento que, en la esfera laboral y del mercado de trabajo, se instituye en términos de los principios de la "flexibilidad horizontal y vertical" y de la "multifuncionalidad" de la fuerza de trabajo (Torres, 2000, p. 24).

Los dispositivos y especificidades generados por la sociedad del conocimiento, en su caso y, como expresión privilegiada de las tecnologías de la información y la comunicación (TIC's). provocan como correlato una transformación radical de la concepción prosaica del conocimiento y de su aplicación al sistema económico/productivo. (Allende, 2001, p. 28).

Desde una perspectiva que parte del análisis de las transformaciones acontecidas en los perfiles y las características de la función trabajo, M. W. Apple señalaba, hace ya tres lustros, lo siguiente: "Durante este último período, las posiciones con un control relativamente escaso sobre el propio proceso de trabajo han experimentado una tendencia sistemática a la expansión. Al mismo tiempo, se ha producido un descenso en las posiciones con elevados niveles de autonomía." (Apple, 1989, p. 39). B. Bernstein, por su parte, interpreta esto como la configuración de una situación de vaciamiento de la identidad del trabajador y de la disolución de esta identidad en una dinámica cuyos referentes estarían dados 
dominantemente por un reconocimiento en las lógicas y los escenarios del consumo (Bernstein, 1998, p. 88).

La incorporación de las TIC's aporta una mayor racionalización a la organización de la función trabajo, y contribuye con la optimización algoritmizada del funcionamiento de las estructuras sistémicas de control, como parte fundamental de la gestión empresarial. Los nuevos dispositivos en los que se sustentan las lógicas y prácticas para la organización y control de la función trabajo, adoptan su condición como tales en la naturaleza algorítmica de las racionalizaciones instrumentales que proveen la ingeniería informática y la cibernética.

Resulta interesante, a propósito, la constatación de que, en la actualidad, ya no baste con la obtención de un producto de calidad. Al mismo tiempo, los algoritmos de la estandarización deben ser aplicados por igual a los procesos; es decir, al comportamiento o desempeño de la fuerza de trabajo o del componente humano implicado en los sistemas de la producción. "La importancia del fin (el producto, el resultado) cede ante los medios, los procesos y los efectos en cualquiera de las etapas. Importan los medios para llegar a los fines e importan las consecuencias de llegar a ellos" (González, 2002, p. 11).

Por tanto, "El trabajo de lo que podría llamarse «empleados semiautónomos» sufrirá sin duda el impacto de esta situación." En este sentido, "Es lógico esperar un crecimiento rápido de los planes y presiones para la racionalización de la administración y el trabajo dentro del propio Estado" (Apple, 1989, p. 39).

Para la educación superior, estas implicaciones van a repercutir en el territorio del currículo. Se estipula que la formación, en los diferentes niveles del sistema educativo, ha de estar sustentada predominantemente en la dimensión del aprendizaje (UNESCO, 1996, p.24); o bien, como se ha enunciado de manera técnica, en la lógica del "aprender a aprender". (Hopenhayn, 2003, p. 177). Diversas variantes especifican esta nueva perspectiva pedagógica: «aprendizaje experiencial», «habilidades transferibles», «resolución de problemas», «trabajo en grupos», «aprendizaje basado en el trabajo» (Barnett, 2001, p. 75). etc. A juicio de este último autor, en su conjunto estas nuevas disposiciones pedagógicas, operarían en el nivel del conocimiento, como un desplazamiento de "la concepción del conocimiento como "saber qué» a "saber cómo»."

Así, las configuraciones pragmáticas que se desprenden de la "apertura global" y de las realizaciones científico/tecnológicas de la sociedad del conocimiento, ofrecen los requerimientos de nuevas competencias y habilidades de formación, acordes con las exigencias de desempeño que el mercado de trabajo establece para los nuevos perfiles profesionales. 
También surge la demanda de una formación abocada a un perfil profesional cifrado en los requerimientos del mercado de trabajo, centralmente articulados alrededor de lo que $\mathrm{B}$. Bernstein denomina como los 'modos genéricos de actuación'. Estos, "se derivan de un análisis funcional de las que se consideran características subyacentes necesarias para la ejecución de una técnica, tarea, práctica 0 , incluso, de un área de trabajo. Estas características subyacentes, necesarias en apariencia, reciben la denominación de «competencias»" (Bernstein, 1998, p. 82).

De acuerdo con lo anterior y, a propósito del principio de la autonomía universitaria, es pertinente señalar lo siguiente. Todo este conjunto de acontecimientos e incidencias que se despliegan como expresión de las transformaciones que hoy acontecen en las esferas de la producción y del mercado de trabajo, establece para la educación superior, una situación en la que, en el ámbito del currículo y de la gestión académica asociada a él: «Los ejes de interés institucional se han desplazado de los proyectos educativos a la organización como meta en sí misma; del sujeto aprendiente y sus procesos, del docente y su trabajo a la eficiencia y la calidad del "producto".» (Garay, 1996, p. 133).

Estos desplazamientos representan reconfiguraciones insoslayables del currículo y del proyecto de formación. Por su parte, los procesos que estos desplazamientos y reconfiguraciones involucran, repercuten en la tesitura del principio de la autonomía universitaria. Se trata de desplazamientos y de reorientaciones, cuyas directrices desencadenan una lógica de tensión para la gestión académica, la cual se ve interpelada a propósito de los fundamentos mismos del proyecto de formación. Este, tal como ya se ha señalado, pasa ahora a ser promovido en términos de la codificación de un perfil de egreso o de formación profesional, dispuesto en razón de su disponibilidad multifuncional para ajustarse a los nuevos requerimientos que la organización y el control de la función trabajo en la empresa desencadenan.

En la óptica de B. Bernstein (1998, p. 41). lo anterior puede ser codificado en términos de la nueva regionalización disciplinaria del conocimiento y de la formación. Las nuevas configuraciones programáticas y de sentido que instituye la política pública, operan un desplazamiento sustantivo en la teleología que da sustento a los imaginarios de la pedagogía. Se trata, así, de una nueva regionalización disciplinaria del conocimiento y de los contenidos académicos del proyecto de formación.

A propósito, se debe agregar que en la respuesta o adecuación que el proceso de formación debe establecer en función de los requerimientos del mercado de trabajo, no figura en principio ni tendría por qué figurar desequilibrio alguno. Es lógico pensar que un 
proceso de formación que no atiende esta dimensión fundamental, no podría considerarse como válido ni legítimo, ni pertinente ni socialmente responsable.

La nueva regionalización disciplinaria del conocimiento, en clave de proyecto y como proceso reciente de transformación pedagógica, incide sobre el proyecto educativo enfatizando su orientación en función de una demanda de mayor articulación intrínseca con el mercado de trabajo y con los requerimientos tecnológicos que este plantea. De este modo $y$, en lo que concierne a las instituciones de educación superior: "la creciente regionalización del conocimiento es un buen indicador de su tecnologización, de la centralización del control administrativo y de los contenidos pedagógicos recontextualizados de acuerdo con reglamentaciones externas" (Bernstein, 1998, p. 81).

\subsection{Diferenciación académica e institucional}

La diversificación de las demandas que proceden de las transformaciones operadas en los sistemas económico/productivos y, asimismo, como resultado de las políticas públicas, repercuten en la educación superior en términos de la generación de procesos de diferenciación y segmentación académica e institucional, "horizontal y vertical" (Brunner, 2002, pp. 116/118). En la óptica de B. Bernstein (1998, p. 90). tal diferenciación conduciría a lo siguiente: "en la educación superior, no sólo hay una estratificación de contextos recontextualizadores y de regionalización, sino también una estratificación de identidades y no sólo de las instituciones, sino también del profesorado y del alumnado."

Las instituciones de educación superior deben realizar el mayor esfuerzo posible para atender procesos y tendencias, tales como la diferenciación y estratificación interna "entre aquellos campos que conducen al empleo y a la movilidad más allá del estado-nación -las ciencias de la técnica global- y aquellos que quizá confinen a sus estudiantes al mercado laboral nacional o regional" (Neave, 2001, p. 47).

Además, con la globalización y la sociedad del conocimiento, la emergencia de otras inéditas configuraciones específicas de diferenciación institucional y de sus ofertas académicas, tiene lugar para la educación superior. Entre ellas y, de manera paradigmática, las que están asociadas con las improntas de obsolescencia que registran en las sociedades contemporáneas, las producciones del conocimiento científico y de las realizaciones tecnológicas.

La impronta de la obsolescencia científico/tecnológica repercute en la emergencia de la necesidad de nuevas modalidades de formación. En este sentido, por ejemplo, cabe mencionar la recurrida modalidad de la formación continua. Esta modalidad de formación 
tomó un auge sin precedentes durante los últimos años, y que, sobre todo, pasó a ser ahora considerada una modalidad relevante de formación, en la medida de que la actualización de competencias del recurso humano calificado o profesionalizado, es una demanda estructural derivada de la obsolescencia científico/tecnológica y de las improntas que estas establecen en el marco de los sistemas económico/productivos y de las estructuras del empleo.

En estas circunstancias, se considera que es necesario desarrollar una nueva habilidad vital: la "entrenabilidad", la habilidad de aprovechar la formación permanente y, de ese modo, poder afrontar las nuevas exigencias del "trabajo" y de la "vida". Esta formación permanente se basará en la adquisición de modos genéricos que, según se prevé, producirán un potencial flexible y transferible, en vez de unas actuaciones específicas (Bernstein, 1998, p. 88).

Desde esta perspectiva, la educación continua ofrece así el carácter de una modalidad de formación importante, en la medida que permite mantener a la fuerza de trabajo, calificada a tono con el continuo proceso de transformación que se opera en el contexto de las realizaciones científico/tecnológicas.

Empero, también sería importante considerar que el significado de la educación continua, no reside tan sólo en las especificaciones mencionadas. En su formato de modalidad de formación que involucra una aplicación y uso intensivo de las TIC's, la educación continua, igualmente, representa una estrategia pedagógica que se vuelve cada vez más indispensable, ya que así lo demandan los procesos cada vez más en boga de recertificación periódica de las competencias profesionales, asumidos crecientemente por las entidades asociativas de los gremios profesionales. De esta manera, la recertificación pasa a ser, en el marco de la globalización y la sociedad del conocimiento, un requerimiento cuya satisfacción perentoria, es demandada por los ritmos cada vez más intensos de obsolescencia en los que cristalizan los códigos de las realizaciones científico/tecnológicas, y que, en su lugar, afectan también a la fuerza de trabajo calificada.

La presión que procede de los agentes del sistema económico/productivo, especialmente de los sectores que poseen comprometidos intereses y establecidas asociaciones con las organizaciones del capital transnacional, acentúa las orientaciones anteriores, con el apoyo que reciben de la política pública estatal y a partir del énfasis que se pone para privilegiar el fomento de la formación profesional en determinados campos disciplinarios. 
Por una parte, el Estado favorece algunas formas de conocimiento: las ciencias naturales, la tecnología, la matemática, la informática y los estudios profesionales orientados hacia la gestión de negocios. Por otra parte, se alienta a la educación superior para que incluya "habilidades transferibles», evidenciando que el Estado no considera suficiente el conocimiento técnico y científico, sino que se requieren cierta capacitación y ciertas competencias que habiliten a los individuos para trascender situaciones específicas y para actuar eficazmente en función de ellas. (Barnett, 2001, p.47).

De este modo, en el contexto del rediseño y supervisión del currículo y del proyecto de formación, ahora organizado atendiendo cada vez más a criterios de diferenciación institucional y académica: "La universidad, al integrarse más con los criterios cognitivos de la sociedad, se ve obligada a mostrar nuevas definiciones sobre lo que se debe conocer $y$ aprender" (Barnett, 2001, p. 67).

\section{A juicio de Muñoz:}

...es evidente que el nuevo orden económico y social ha exigido un replanteamiento estructural de los contenidos, métodos y técnicas de la educación, de la investigación y la extensión universitaria, de la orientación de las profesiones en los mercados de trabajo, de la producción y distribución de conocimientos y su organización disciplinaria, y de las relaciones de la universidad con la sociedad y el sistema productivo (Muñoz, 1995, p. 14).

La modalidad de la educación a distancia, por otra parte $\mathrm{y}$, como correlato o complemento de lo anterior, también ve modificada su naturaleza y condiciones, a partir de la incorporación de las TIC's en la organización pedagógica del proceso de formación. De una modalidad de formación que tenía anclada su orientación en función de prestar atención a una demanda educativa con limitaciones para asumir los requerimientos de un proceso común de carácter presencial, la educación a distancia se transforma ahora en una modalidad que permite a las instituciones con disposición de producir y hacer uso de desarrollos tecnológicos sofisticados, impulsar una oferta de servicios educativos que tiende a invadir, incluso, los espacios tradicionalmente definidos para el desarrollo de la modalidad de formación presencial. 
Otro de los aspectos cruciales que es posible advertir en los esquemas de desarrollo, en donde se expresan las tendencias de diferenciación y de segmentación académica e institucional en la educación superior, lo configura la eclosión de una oferta educativa de nivel superior, la cual, no obstante, ya no está situada privilegiadamente en el nivel específico de la formación universitaria. Desde hace ya una década, R. Kent señalaba que, en la educación superior latinoamericana, la diferenciación académica e institucional presenta una situación "donde el sector privado ha crecido intensamente [...] y donde las instituciones de tipo no universitario representan hoy la mayoría." En consecuencia: "No se puede hablar ahora de la universidad latinoamericana como si fuera equivalente a la educación superior" (Kent, 1995, p. 72).

Esta diferenciación, que expande y estructura en diversos subniveles y teleologías de formación el nivel de la educación superior, es quizá el rasgo más característico que, como factor decisivo, influye en la diferenciación académica e institucional. Tal orientación entronca con los procesos de diversificación de una oferta académica, la cual está dirigida privilegiadamente a brindar respuesta a las demandas que derivan del sector económico/productivo y del mercado de trabajo. Es decir, se trata de una oferta académica con alcance de carácter puntual, y sin perspectiva de desarrollo estratégico. En ella operan disposiciones que organizan el proyecto de formación, en función de los requerimientos técnicos y de corto plazo del mercado de trabajo.

Todas estas tendencias y requerimientos confrontan la gestión académica e institucional de la educación superior y, en su caso, al principio de la autonomía universitaria, con la emergencia de nuevas y urgentes dinámicas de transformación y cambio.

Dentro de los rasgos característicos que otorgan su fundamento al principio de la autonomía universitaria, se encuentra el de la organización y orientación apropiada del quehacer académico, en función de lo que las propias instituciones de educación superior consideran como un proyecto de formación socialmente relevante.

En el marco de la educación superior pública, el concepto de desarrollo nacional involucra una perspectiva compleja que abarca una diversa multiplicidad de actores y sectores sociales. De igual modo hace intervenir muy distintas dimensiones, niveles y escalas de carácter estructural y estratégico. De esta forma, es preciso tener en cuenta que "las relaciones universidad-sociedad en nuestros países van más allá de las relaciones universidad-sector productivo" (García, 1995, p. 59). Para estas instituciones, el desarrollo nacional tiene que ver sustantivamente con procesos estructurales, en donde participan, de manera esencial, los sistemas económico/productivos. No obstante, por supuesto, la 
consideración de este concepto no remite ni se restringe a la dinámica e intereses que pudieran plantear unilateralmente los sectores empresariales o los actores del sistema económico/productivo.

Lo anterior permite afirmar con claridad que los fundamentos del principio de la autonomía universitaria, se encuentran presentes en la actualidad y de manera sistemática en la definición de su propio proyecto de formación y en su capacidad para hacerlo valer, como una contribución sustantiva y a profundidad que las instituciones de educación superior proporcionan a la sociedad.

\subsection{Expansión de la demanda y la privatización}

Otro ámbito relevante que problematiza el tema de la autonomía universitaria, lo establece el incremento o masificación de la demanda de los servicios educativos de nivel superior. La constitución acelerada durante los últimos años de una demanda masificada, no representa únicamente un cambio cuantitativo; también lo es, superlativamente, de naturaleza cualitativa. En breve, la expansión de la demanda comporta, por un lado,

el agotamiento de un patrón orientado hacia la formación de las élites y de la burocracia gubernamental; del otro, la necesidad de redimensionar el sistema en dirección con una educación de masas, capaz no sólo de absorber un número creciente de aspirantes como también de formar, a ritmo acelerado, profesionales en nuevas carreras y áreas de especialización. (Klein y Sampaio, 2002, p. 31)

A juicio del Banco Interamericano de Desarrollo (BID): "Aún cuando la educación superior haya desempeñado papeles importantes durante siglos, jamás hubo antes una necesidad tan grande de recursos humanos que estuvieran bien formados mediante la educación formal avanzada." (1997, p. 2). La justificación de este enunciado se configura a partir de la importancia que, como ya se ha indicado, adquiere cada vez más el sector terciario de la economía, en tanto desarrollo específico que concitan la globalización y la sociedad del conocimiento. De igual manera, la nueva funcionalidad que se establece para la fuerza de trabajo, se encuentra implicada, como expresión de los requerimientos que plantean las realizaciones científico/tecnológicas de la sociedad del conocimiento.

Por su parte, en lo que concierne al vínculo de la expansión de la demanda con la emergencia y desarrollo acrecentados de la oferta privada de los servicios educativos, este no tendría necesariamente por qué constituir un problema especial, si no fuera porque en ello está implicada la noción de la educación superior en tanto bien público. La expansión de 
la demanda, así se le reconoce generalizadamente, configura una problemática y una realidad que, en todo caso, no ha podido ser asumida por las instituciones de educación superior pública.

No obstante, originada, precisamente, en un contexto en el que la política pública estatal se concentra en la reducción del financiamiento y en privilegiar la orientación de las dotaciones presupuestarias hacia los niveles de la educación básica, la eclosión de la demanda de formación en el nivel superior, posibilitó el incremento acelerado de los establecimientos de la educación superior privada, con el apoyo explícito de la política pública estatal.

En el ínterin, las condiciones institucionales de la educación superior pública, se vieron confrontadas con la distribución de un amplio escenario de servicios educativos que la política pública estatal incentivó e intensificó, entre otros mecanismos, mediante la apertura y el fortalecimiento de programas e instituciones de crédito, específicamente destinados a financiar la realización de estudios de nivel superior. De este modo, la política pública de financiamiento a la educación superior, da un impulso sustantivo al desarrollo de los establecimientos privados, como una forma de abrir nuevos espacios que permitan atender la eclosión de la demanda. Se trata, así, de una política pública que impulsa la privatización de los servicios educativos, por la vía del aprovechamiento de la eclosión de la demanda.

En algunos países de América Latina, la oferta privada de servicios educativos ha llegado ya a representar, en un horizonte temporal de poco más de una década, el más alto porcentaje de captación de la demanda (Balán y García, 2002, pp. 180-181).

A propósito, el Banco Mundial (1999). en su documento de política del año 1999, La educación en América Latina y el Caribe, considera como un logro laudable de la educación superior latinoamericana, que un tercio de los estudiantes del tercer nivel estuviera, al final de la década de los 90, matriculado en instituciones privadas.

Dos riesgos importantes pueden ser identificados, a partir de la situación que hace intervenir esta particular resolución de la relación entre la expansión de la demanda y la privatización de los servicios educativos. El primero de ellos, en perspectiva de la educación superior en tanto bien público, está dado por la creciente tendencia a transformar los servicios de educación en una mercancía. El segundo, remite a la configuración de una posible nueva disposición elitizada del proyecto de formación, el cual, esta vez ya no estaría referido a la formación de élite de las clases gobernantes, sino a concentrarse en una formación de alta calidad en función de aquellas carreras y profesiones que el mercado global demanda, y que determinados estratos sociales están interesados en adquirir. 
...un dato que llama la atención en las universidades estatales es el aumento del porcentaje de estudiantes que provienen de hogares en los que el padre y la madre cuentan con escolaridad universitaria, contrario a lo que ocurría en décadas pasadas, cuando un porcentaje significativo de estudiantes procedía de hogares cuyos padres tenían grados de escolaridad menor, lo que convertía a las entidades de educación superior en un importante mecanismo de movilidad social (Estado de La Nación, 2003, p. 108).

En este aspecto, las implicaciones y riesgos para la autonomía universitaria, todavía son apenas percibidos. Aún está por analizarse cuáles podrían llegar a ser las repercusiones que, desde la dimensión y dinámicas de la privatización, podrían llegar a configurarse para la educación superior pública; sobre todo, a partir de las tendencias que configuran los procesos impulsados por el Acuerdo General de Comercio de Servicios (AGCS) de la Organización Mundial del Comercio (OMC). de igual modo por la apertura de los escenarios de liberalización comercial propugnados en el marco de los tratados de libre comercio (TLC's).

\subsection{La política pública}

Durante los últimos años, la política pública, en su formulación y aplicación a la educación superior, involucra y se hace cargo, especialmente, de canalizar los intereses y expectativas que proceden de dos conjuntos de actores principales. En primer lugar, toman en cuenta a los así denominados "sectores más dinámicos y modernizantes" de la sociedad. En segundo lugar, dichas políticas tienen además como referente, las propuestas de los más importantes organismos multilaterales: Banco Mundial, Banco Interamericano de Desarrollo (BID). UNESCO, CEPAL, etc. Dentro del primer conjunto de actores, un lugar destacado lo ocupan aquellos que, ubicados en la dimensión económica y del sistema productivo, tanto en la escala local nacional como en la internacional, mantienen una dinámica relación de sus actividades con los procesos y exigencias de modernidad que implican la globalización y las realizaciones científico/tecnológicas asociadas a esta. En ambos casos, se trata de actores cuyas demandas inciden sobre la formulación de la política pública, así como en el establecimiento de diferentes mecanismos para organizarla y llevarla a ejecución.

El Estado, a través de instrumentos, tales como el financiamiento y los dispositivos de control específicos; entre ellos, el de la evaluación, se ha hecho cargo de impulsar una política pública de educación superior, acorde con las perspectivas que promueven los 
actores mencionados y, mediante los cuales, orienta un cambio de estas instituciones en función de una racionalidad que busca organizarlas en un sistema "más moderno y eficaz" (Klein y Sampaio, 2002, p. 31).

En lo que concierne a la política de financiamiento, a partir de los Programas de Ajuste Estructural (PAE's) de los años '80 y, lo mismo durante la década de los '90, las instituciones de educación superior se vieron inscritas en una situación en las que se les llegó a poner agudamente en cuestión, planteándoseles inéditas exigencias. Entre estas, la rendición de cuentas ante los correspondientes organismos del Estado, al mismo tiempo que el sometimiento a los procesos de evaluación, los cuales fueron organizados de conformidad con criterios de eficiencia y eficacia tomados de los nuevos modelos de la gerencia empresarial.

No obstante, la política pública estatal, en materia de financiamiento, tampoco tiene que ver exclusivamente con una aplicación simple de los criterios de eficiencia y eficacia, emblemas en los que se sustentó para estas instituciones, la doctrina del ajuste estructural. Esta cuadriculación de la política pública implica la solicitación y el condicionamiento de un modelo distinto de universidad.

En su forma más coherente y desarrollada [...] asocia el financiamiento con indicadores de desempeño, implica una definición previa y externa a las propias universidades de las funciones sociales que ellas deben desempeñar y promueve su autonomía administrativa. [...] // Este tipo de reforma tiene carácter claramente instrumental. Se trata de crear mecanismos y organizaciones dotados de eficacia para enfrentar los problemas asociados con la expansión y la multiplicación de las funciones del sistema de educación superior (Ribeiro, 2002, p. 25).

De manera especial, los instrumentos y dispositivos del financiamiento y la evaluación, asociados con las tendencias y procesos estructurales de la globalización y de la sociedad del conocimiento, induce a que, a juicio de R. Kent, se configure una situación en la que se puede afirmar que "los valores y las estructuras típicas del modelo que históricamente se ha conocido como universidad pública en América Latina han llegado a su límite" (Kent, 2002, p.257).

Esta constatación, cuyo registro data ya desde la década de los 90, en el caso del principio de la autonomía universitaria, conduce naturalmente a una situación en la que se considera la necesidad de replantear cuál es la vigencia real que, en la actualidad, asiste a 
este fundamental pilar de historicidad y de la identidad institucionales de la educación superior pública.

De este modo, en el presente y, a partir de los derroteros que trazan las políticas públicas, las instituciones de educación superior pública han dejado, en particular, de ser vistas como instituciones en las que los actores externos, verbigracia, autoridades gubernamentales, organismos multilaterales, agentes del sector empresarial, organizaciones de la sociedad civil, en el pasado no intervenían sustancial ni tan directamente, como lo hacen ahora. Esta condición de identidad institucional y de sustentación de esta identidad en el principio de la autonomía universitaria, especialmente en la dimensión académica, tenía claramente definidos sus horizontes programático y de gestión. En décadas anteriores, la institución de educación superior pública era consciente de ello y, como tal, operaba consistentemente, haciendo valer tal condición.

No obstante, estas condiciones han visto modificadas sus coordenadas de manera sustantiva durante los últimos años (García, 1995, p. 62). La emergencia de los escenarios de la privatización de los servicios educativos; las condiciones de negociación del financiamiento; la existencia de una demanda, cuya configuración es cada vez más compleja y diferenciada, se constituyen en instrumentos de gestión y de aplicación de la política pública en materia de educación superior, cuya implicación es innegable a propósito de los alcances y actualizaciones que puede presentar el principio de la autonomía universitaria.

\section{Principio de autonomía universitaria y concepto de 'autonomía relativa'}

\subsection{Especificidades del principio de la autonomía universitaria}

Comúnmente, por autonomía de la educación superior, se entiende el derecho legítimo a definir cuál orientación deben dar estas instituciones a su quehacer académico, así como a discernir los criterios para organizar su propio proyecto de formación. Esta acepción del principio de autonomía otorga a las instituciones de educación superior, la prerrogativa de llevar a cabo una definición autónoma de lo que, ellas mismas, con base en el conocimiento que poseen de su entorno y de las realidades y necesidades societales identificadas, consideran como la orientación que deben dar a su quehacer académico, en función de su contribución y compromiso con la sociedad y con el desarrollo nacional.

En una de sus definiciones tradicionales: "Por autonomía universitaria deberá entenderse, en suma, que la universidad, en el cumplimiento de sus fines, no depende de 
ninguna persona u organismo extraño a ella, ni puede ser interferida en su existencia y actividades" (SP/CSUCA, 1959, p. 9). Con sustento en el principio de la autonomía, la universidad no solo dispone las modalidades de su gobierno y la gestión y organización administrativa de los recursos y presupuestos que requiere para operar. De igual modo, define también su proyecto académico y de formación, los rasgos o contenidos y la proyección de su oferta académica, el tipo de formación que considera pertinente proporcionar a los estudiantes.

La asunción de este enfoque es reafirmada por la UNESCO/CEPAL, a inicios de la década de los 90, en el documento Educación y conocimiento: eje de la transformación productiva con equidad. En este documento, en lo que concierne a la educación superior, se aboga "por reconocer a los establecimientos universitarios su libertad para emprender tareas acordes con el proyecto institucional de cada uno, con plena autonomía e independencia en la gestión de sus asuntos económicos, administrativos y financieros" (Kent, 1995, p. 73).

No obstante, a raíz de los determinantes de transformación que la educación superior pública acusa, como resultado de los factores enunciados ya anteriormente, así como, de manera especial, por efecto de las directrices e incidencias normativas que derivan de la política pública durante los últimos años, la autonomía universitaria, ahora constituye uno de los pilares de la educación superior que también, en el presente, acude a la circunstancia de verse puesto en cuestión, en su tradicional formulación como tal.

Una primera observación necesaria. El análisis del principio de la autonomía, en perspectiva de lo anterior, tiende a perder consistencia, si se le aborda al margen de la codificación del proyecto de formación que, desde los actores externos, la política pública estatal, el sector empresarial, los organismos multilaterales, ahora se establece para estas instituciones. La heurística del principio de la autonomía universitaria, contribuiría muy poco, en función de caracterizar lo que la educación superior pública actualmente representa, si tan solo se le mantuviera operando y fuera asumido bajo la condición de un enunciado abstracto y principista.

Para la educación superior pública, el principio de la autonomía universitaria remite históricamente a un quehacer académico y cultural sustentado en disposiciones de diálogo, de intercambio diverso y de constitución de una sensibilidad y una actitud críticas. Este principio define el carácter de una institución que se unifica "por el contenido universal de su instrucción, por permitir el libre flujo de ideologías y por acompañar la transmisión de los fundamentos científicos a una conciencia humanista de sus fines y consecuencias" (SP/CSUCA, 1996, p. 21). 
Así, la autonomía se pone de manifiesto y se historiza, en su naturaleza, como un rasgo esencial e irreductiblemente inherente a la educación superior pública. Además, permite a estas instituciones configurar su identidad y su desempeño, al encontrarse inscritas en el contexto del sistema institucional del país.

En general la educación superior pública tiene la distinción institucional de constituir un patrimonio y un conjunto de políticas, programas, proyectos y cursos de acción de alto valor actual y estratégico, para prestar una contribución significativa a un proyecto nacional de desarrollo basado en la justicia social, la equidad, la democracia y el mejoramiento de la calidad de vida para el conjunto de la sociedad (González, 2004a, p. 4).

Segunda observación necesaria. Lo anterior quiere decir, que el principio de la autonomía universitaria, tampoco tiene nada que ver con prerrogativas institucionales que se pudieran definir, simplemente, como un atributo más de la institución. Antes bien y, fundamentalmente, la autonomía constituye el eje que dota de sentido a la relación que la institución de educación superior establece de manera compleja y dinámica con la sociedad, lo mismo que con los diversos agentes del sistema institucional del país. A esto, naturalmente, se debe añadir la interacción que ella establece, asimismo, con los actores y agentes que operan en la escala internacional, en particular, los organismos multilaterales.

En el ámbito de los procesos y prácticas de la educación, la complejidad ha producido efectos que es posible identificar en múltiples planos. La educación es vista cada vez menos como un proceso meramente resultante de otras determinaciones sociales y sin perder de vista los vínculos que mantiene con el resto de las estructuras de la sociedad, se le reconoce como un ámbito funcionalmente diferenciado, esto es, con ritmos, dinámicas y lógicas propias conforme a las cuales "responde" a las irritaciones que le vienen del entorno social. (Granja, 2003, p. 9)

En el presente, difícilmente se podría negar que, en países como los latinoamericanos y, aún más especialmente, en contextos sociohistóricos como el que caracteriza a los países de Centroamérica, la educación superior pública continúa ostentando el carácter de un escenario de formación y de prestación de unos servicios de naturaleza muy significativa para los sistemas económico/productivos y para el desarrollo nacional. Así, por ejemplo, en el quehacer de estas instituciones, sigue estando sustentada la proporción mayoritaria de la producción endógena de conocimiento científico y tecnológico (BID, 1997, pp. 5-6). Sin embargo, tampoco basta simplemente con constatar esto. 
El aporte que la educación superior pública proporciona, tiene la cualidad de ser social e históricamente relevante, porque no solo así está establecido en las respectivas declaraciones de misión de estas instituciones, $Y$ desplegar la constitución de un aporte relevante, representa para estas instituciones, cumplir prospectivamente con las directrices centrales que les trazan sus propias declaraciones de misión: una relación aportante, crítica, constructiva y de compromiso permanente con el desarrollo en su conjunto de la sociedad. Valga recalcarlo, un aporte que, en su caso, todavía recientemente ha enmarcado la UNESCO en términos de: "la paz, la justicia, la libertad, la igualdad y la solidaridad" (Conferencia Mundial sobre la Educación Superior, 1998, p. 22).

Tradicionalmente, el principio de la autonomía universitaria constituye uno de los rasgos matriciales más preclaros que dan su sustentación institucional a la educación superior pública. En América Latina, en su origen, este connotado principio está asociado, por una parte, con una decidida disposición de laicidad -legado del movimiento y las reformas de Córdoba; y, por la otra, con el establecimiento de un moderno y apropiado modelo de universidad, que deposita la definición de sus fundamentos de manera privilegiada a partir de "una base humano-racional absoluta, constituida en ideal y en deber ser" (Garay, 1996, p. 130).

Empero, con las implicaciones estructurales que acarrean la globalización y la sociedad del conocimiento, las condiciones de desenvolvimiento institucional y programático para la educación superior pública, se vuelven diversas y variables.

El perfil de desempeño y aquello que se solicita ahora a estas instituciones, no consiste en demandas ancladas únicamente en los códigos de las normativas y de la reglamentación que la política pública instituye en términos instrumentales de control estatal administrativo. Antes bien, todo el tejido de requerimientos y la estrategia de intervención que opera la política pública toman, de igual manera, su configuración proyectiva en la forma de contenidos programáticos que se aplican a la definición de determinados productos, en tanto resultados que se demandan del proceso de formación. En otras palabras, son directrices programáticas que se aplican a la búsqueda de determinados perfiles de profesionalización. En este sentido: "Las reformas de las profesiones y la pedagogía están vinculadas a los cambiantes problemas del saber y de la regulación de la sociedad" (Popkewitz, 1997, p. 89). Por tanto, cualquier cosa que sea lo que ahora se solicita a la educación superior, deviene también en la forma de la constitución de toda una nueva teoría pedagógica. $Y$ esto es fundamental de tener en cuenta, a propósito del principio de la autonomía universitaria.

Aún cuando tradicionalmente y, por lo común, tanto autoridades del Gobierno, lo mismo que las propias dirigencias universitarias y las comunidades académicas de la 
educación superior, hayan podido llegar a coincidir en la perspectiva de que "las universidades constituyen un instrumento fundamental para la modernización de la sociedad" (Ribeiro, 2002, p. 11). este imaginario, no obstante, no alcanza todavía a constituir un significante de configuración y asimilación de valor homogéneo para todos.

Las instituciones $-\mathrm{y}$ particularmente las educativas- son formaciones sociales $y$ culturales complejas en su multiplicidad de instancias, dimensiones y registros. Sus identidades son el resultado de procesos de interrelaciones, oposiciones y transformaciones de fuerzas sociales y no de una identidad vacía o tautológica de la institución "consigo misma". (Garay, 1996, p. 129).

Lo que cada uno de los actores interesados en la definición y establecimiento de la política de educación superior esboza, como su propia expectativa y demanda, no constituye naturalmente una orientación a cuyo efecto los demás actores participantes estén dispuestos a otorgar sin más, su nuda aquiescencia. Las políticas de educación superior pública involucran la peculiar característica de que se definen en el marco de un conjunto de alternativas en el que, indeclinablemente, confluyen intereses disímiles por provenir de las expectativas de agentes diversos (Neave, 2001, pp. 20-21).

Las políticas públicas abocadas a la reforma de los sistemas educativos en América Latina, durante los últimos tres lustros, han hecho énfasis en promover transformaciones en los ámbitos "organizativos, financieros, cualitativos y de articulación sistémica. Aunque existen experiencias diversas, los énfasis han tendido a recaer en las dos primeras áreas" (CEPAL, 2000, p. 96). Según esto, los ámbitos privilegiados, objeto de la política pública estatal en materia educativa, tienen como núcleos de anclaje, aspectos neurálgicos que, en el caso de la educación superior, han provocado polémica y no pocos desacuerdos. Aún cuando la política pública se ocupe mayormente del nivel de la educación básica (primaria y secundaria). no obstante, las propuestas de reestructuración organizativa de las instituciones educativas, también afectan al nivel de la educación superior pública.

Desde el punto de vista del principio de la autonomía universitaria, este desequilibrio de asimilación y de asunción política y programática es relevante, puesto que en la tensión que se configura en la intersección de estos intereses diferenciados, es donde se generan y definen la posibilidad y las características de su anclaje, así como los espacios y dimensión específica que permiten establecer la verificación de sus alcances efectivos.

A propósito, cabe implicar la pista heurística que proporciona la categoría de "campo recontextualizador pedagógico' (CRP). acuñada por B. Bernstein. "El campo 
recontextualizador tiene una función crucial en la creación de la autonomía fundamental de la educación" (Bernstein, 1998, p. 63). Esta condición fundamental de autonomía, cifrada en situación de interlocución compleja con las políticas públicas del Estado, acusa hoy una posición crítica en la medida de que estas, a través de las disposiciones y dispositivos del "campo recontextualizador oficial" (CRO). buscan debilitar el CRP y "pretenden reducir la relativa autonomía sobre la construcción del discurso pedagógico y sus contextos sociales" (Bernstein, 1998, pp. 63-64).

El "campo recontextualizador pedagógico", "principio recontextualizador" del "discurso pedagógico', opera como un mecanismo que "se apropia de, recoloca, reenfoca y relaciona selectivamente otros discursos para construir su propio orden y sus propios ordenamientos" (Bernstein, 1997, p. 189). De este modo, de nuevo emerge aquí la constatación de la existencia de un conflicto primordial, en la base de las configuraciones de la institución educativa, que las determinaciones dominantes de la política pública se ven obligadas a resolver, mediante la formulación de las correspondientes estrategias pedagógicas. En términos genéricos: "Podemos definir la autonomía relativa del discurso pedagógico en la medida en que se permite que existan los campos pedagógicos recontextualizadores (CPR) y afecten a la práctica pedagógica oficial" (Bernstein, 1997, p. 203).

En el marco de dicha interacción compleja, la institución de educación superior asiste al desafío de revisar el carácter específico que la identifica, como institución educativa; el desafío por preservar su diferencialidad como tal y de validar sus especificidades académicas, frente a las codificaciones, disposiciones de contenido y la teleología que, mediante la política pública, despliega el "campo recontextualizador oficial" del Estado.

En Costa Rica, durante los últimos años:

Los cambios implicados responden a la dinámica interna propia de la institución, pero también provienen del entorno; ellos configuran la necesidad de atender las nuevas demandas, y asumir los nuevos retos y desafíos con planteamientos actualizados y reflexivos (González, 2004b, p. 1).

El desafío no es simple. La filtración de esa racionalidad pedagógica a la que B. Bernstein califica en términos de "entrenabilidad", tiende a hacerse su lugar y a dotarse de legitimidad, a través del propio enfoque pedagógico que incorporan los actores internos de la educación superior. Cuando esta situación acontece, la visión pedagógica involucrada y sus horizontes axiológicos, pueden llegar a adquirir un alto grado de sintonía con las 
pretensiones formativas y de profesionalización del enfoque oficial de la política pública del Estado, y con la de los agentes del sector productivo y empresarial.

\subsection{El concepto de 'autonomía relativa'}

El concepto de 'autonomía relativa' adquiere relieve como una problematización explícitamente implicada y central, especialmente en las teorías de la reproducción cultural.

En su texto, La reproducción, Bourdieu/Passeron señalan que la autonomía institucional en la educación superior, se constituye a partir del umbral que articula una "doble verdad": la de la función externa de "conservación social" de la institución, y la de la “lógica interna” de su funcionamiento" (Bourdieu/Passeron, 1998, p. 229). Así, estos autores, consideran que la autonomía, en una institución de educación superior, será siempre relativa. A su juicio, esto es así en función de la tensión que, estructuralmente y de manera fundante, caracteriza la constitución de identidad de toda institución de educación superior, en la medida en que esta responde a un contexto específico de sociedad y, consecuentemente, se encuentra inscrita en las coordenadas de un sistema institucional específico.

Aunque involucre la objeción de pecar en exceso de obviedad, cualquier propuesta e iniciativa que se adopte para el análisis de la autonomía, plantea el necesario requerimiento de no restringir el enfoque al reduccionismo que otorga a la institución de educación superior, una "independencia absoluta"; o bien, por el contrario, que solo la considera como el reflejo "de un estado del sistema económico o la expresión directa del sistema de valores de la «sociedad global»." En cada caso, aún cuando estos dos distintos referentes de abordaje resultan, evidentemente, del todo insuficientes, no obstante, es preciso mencionarlos, ya que con insistencia tienden a formar parte de las premisas, a partir de las cuales, diversos actores ponen en perspectiva sus respectivos planteamientos.

Para Bourdieu/Passeron, la institución de educación superior es de por sí una entidad compleja. Por esta razón, al abordar el estudio de las condiciones, significados e imaginarios que en ella desarrollan el concepto y las prácticas de la autonomía, la realización del análisis obliga a relacionar su identidad y su perfil de historicidad con "las características, presentes y pasadas, de su organización y de su público con el sistema completo de relaciones que se establecen, en una formación social determinada, entre el sistema de enseñanza y la estructura de las relaciones de clase" (Bourdieu/Passeron, 1998, p. 229).

De este modo planteado, el concepto de autonomía relativa que La reproducción propone, aconseja el requerimiento de prestar atención a los diversos elementos centrales; 
vale decir: espacios institucionales, proyecto académico y actores sociales e institucionales que intervienen en los espacios institucionales de la educación superior y que, de este modo, se constituyen en referentes, a partir de las cuales, la institución se dota de las especificidades de identidad y de historicidad que le son características.

Estos elementos de referencialidad suscitan, tanto en la dimensión de su proyección externa, como en la de su organización y establecimiento de dinámicas y prácticas internas, que la institución de educación superior no pueda ser simplemente asumida, como si se tratase de una organización basada en reglas y normas yuxtapuestas de carácter instrumental administrativo. Antes bien, habría que entenderla como un organismo siempre en pleno proceso de desarrollo y de cualificación; como una entidad cuya impronta fundamental consiste precisamente en mantenerse inscrita en una dinámica de transformaciones constantes.

Según lo anterior, lo que estaría en juego, a partir de la consideración y estudio de la autonomía, no residiría a priori en una defensa formal de la institución, sino de la puesta en escena de lo que podría denominarse, como el ejercicio de un principio de institucionalidad. Esta noción es inherente a toda institución y es la esencia de toda configuración de institucionalidad. A partir de su actualización, las instituciones se procuran sus propios fundamentos y definen sus características específicas.

No obstante, se constituiría una expectativa teórica aún insuficientemente fundada, asumir que desde el planteamiento esbozado en La reproducción, se podría sin mayor dilación, pasar a definir la naturaleza de la autonomía, como una relación de tensión o de interacción compleja entre lo que, por una parte, la institución educativa establece como su propia lógica interna de funcionamiento, y lo que, por la otra, organiza y proyecta como contenido esencial de su función externa. En otras palabras, el planteamiento formulado en La reproducción, aporta todavía insuficientes elementos explícitos, como para dar al concepto de autonomía, una acepción en términos de una relación en la que, frente a los requerimientos, presiones y demandas "de la sociedad", la institución educativa pudiera disponer por su propia cuenta de una posición que le permitiera mantener siempre un umbral apropiado de sistémica, reflexiva y prospectiva asunción programática y política de su condición como tal.

De lo que se trataría, en este caso, es de afirmar la validez de una visión teórica, según la cual, se podría atribuir a la institución educativa, las condiciones de una entidad institucional capaz de conferirse un discernimiento relativamente autónomo, respecto de los requerimientos, presiones y demandas que la sociedad le plantea. Y que, además, a partir de 
los resultados de tal discernimiento, le permitiera, asimismo, definir las políticas y tomar las decisiones pertinentes, a propósito de las configuraciones de sentido y de las orientaciones programáticas que dispone dar a su proyecto educativo.

La insuficiencia en cuestión, reside en que Bourdieu/Passeron plantean la autonomía relativa de la institución educativa, como algo que consistiría predominantemente en la verificación sistémica de un juego de disimulación. A su juicio, la institución educativa involucraría el carácter de una institución que se hace cargo de la reproducción de la 'violencia simbólica' y de la 'arbitrariedad cultural', propias del sistema de códigos y representaciones que promueve la cultura dominante (Bourdieu/Passeron, 1998, pp. 44-45). Los dispositivos simbólicos que articulan los imaginarios de la cultura dominante, se canalizarían a través de la institución educativa, sin más mediaciones que las necesarias para preservar una apariencia de institución al servicio abierto de los requerimientos e intereses educativos diversos de la sociedad.

Por consiguiente, La reproducción señala que, en su operacionalización medular de sentido y como mecanismo que organiza las prácticas institucionales, la imagen de la autonomía contribuye a "disimular las funciones sociales" que la institución educativa está encargada de realizar y que, además, por esta misma vía del disimulo, despliega un mecanismo que le permite "realizarlas más eficazmente" (Bourdieu/Passeron, 1998, p. 229). De este modo, la propia estructuración pedagógica de la institución, se hallaría así organizada en función de preservar y reproducir lo que, por su parte, constituye la estructura prevaleciente de las desigualdades de clase.

La institución educativa, considerada en tales términos, es endosada de una función y de una identidad que la convierten en depositaria y reproductora de esquemas racionalizadotes; por ejemplo, de lo que se considera como "inteligente", o de lo que es definido como "la inteligencia". Todo ello en razón de superlativizar y sacralizar como tal "las características de aquellos que transitan por ella exitosamente" (Fernández, 1998, p. 23). Esta determinación de "la inteligencia", que se expresa en una representación mediada por condicionamientos histórico/sociales y culturales específicos, confiere a la institución educativa, un sesgo discriminador, mediante el cual, se plasma la reproducción de las desigualdades sociales y culturales. En retribución, ella obtiene su prerrogativa de autonomía relativa. Por medio de las características institucionales que de este modo despliega, "tiende objetivamente a producir, mediante el enmascaramiento de la verdad objetiva de su funcionamiento, la justificación ideológica del orden que produce a través de su funcionamiento" (Bourdieu/Passeron, 1998, p. 264). 
Este concepto de autonomía relativa de Bourdieu/Passeron, por su parte, es sintetizado por B. Bernstein del siguiente modo:

[...] la autonomía relativa crea un espacio en el que la autonomía (la independencia relativa del sistema educativo frente a la regulación externa) otorga al sistema educativo una apariencia de neutralidad, que es el origen del disimulo, del sesgo de la naturaleza arbitraria del sistema, sus procesos y textos. Esta autonomía relativa disimula, por tanto, el sesgo de clase de la educación (Bernstein, 1997, p. 177).

Al respecto, La reproducción introduce la categoría de 'acción pedagógica' (AP). Esta categoría es entendida como el eje articulador, en donde se cristaliza el quehacer de la institución educativa. A partir de las propias determinaciones en las que se basa el diseño de los fundamentos curriculares que dan sustento al proyecto educativo, se configura la notación de un entramado de interacciones, cuyos códigos pasan a ser de una naturaleza distinta:

Las relaciones de fuerza están en el origen, no solamente de la AP, sino también del desconocimiento de la verdad objetiva de la AP, desconocimiento que define el reconocimiento de la legitimidad de la AP y que, como tal, constituye su condición de ejercicio. (Bourdieu/Passeron, 1998, p. 55)

Por una parte, la categoría de acción pedagógica destaca que, desde la propia forma, sentido e intencionalidades que articulan los fundamentos para la estructuración y organización del currículum -la matriz fundante del proyecto de formación, emergen las condiciones que atraviesan y las directrices que determinan la lógica interna de funcionamiento de la institución, tanto como la proyección de su función externa, en términos de disimulación o de enmascaramiento.

No obstante, la configuración de la acción pedagógica, su condensación en normas, reglas y lineamientos pedagógicos específicos, sólo ocurren a partir de su inscripción en el contexto de una matriz de relaciones de fuerza. En cualquier caso, esta matriz de relaciones de fuerza, en tanto que constituye su origen mismo y su posibilidad de ser producida, restituye a la acción pedagógica de nuevo, el carácter de una entidad irreductible que no puede ser subrogada a estrategias homogeneizantes ni a la expresión unilateral de los deseos, intereses y propósitos que promueven los actores de la política pública dominante.

De este modo, más allá de un planteamiento que pudiera agotarse en el esquema simple y positivista de considerar las relaciones de clase, como aspectos de determinación unilateral, Bourdieu/Passeron enfatizan en la categoría de 'relaciones de fuerza' que "las Volumen 6, Número 1, Año 2006, ISSN 1409-4703 
relaciones de la función externa de la institución educativa están mediadas por o inscritas en "la estructura de las relaciones de fuerza que se establecen en un momento dado entre las clases sociales" (Bourdieu/Passeron, 1998, pp. 229-230).

De esta forma, la categoría de relaciones de fuerza proporciona al estudio de la institución educativa, una heurística anclada en la consideración de su historicidad específica, y permite avanzar en la identificación de sus particularidades, como institución que, en diversos sentidos, se encuentra inscrita en un contexto sociohistórico definido por la implicación compleja y dinámica del encuentro entre actores diversos.

Es en este sentido, precisamente, que B. Bernstein elabora una recuperación y profundización de los planteamientos esbozados por Bourdieu/Passeron, a partir de la formulación de su categoría de 'dispositivo pedagógico'.

El dispositivo pedagógico es, esencialmente, un dispositivo para traducir las relaciones de poder a discursos de control simbólico y para traducir éstos en relaciones de poder. En la medida en que el dispositivo pedagógico traduzca las relaciones de poder a discursos de control simbólico, éstas regularán o tratarán de regular en el discurso lo que está "todavía por pensarse", que es un potencial del discurso realizado por el dispositivo mismo (Bernstein, 1997, p. 210).

En lo anterior, se pone de relieve la impronta paradójica que define el carácter de la autonomía. Por una parte, la autonomía representa un principio de validez y legitimidad irreductibles. Por otra, no obstante, su alcance es y será siempre estrictamente relativo. En este sentido, la constitución de la autonomía relativa involucra una fundamental implicación de alcance político; es decir, se constituye en un dispositivo que se resuelve en un entramado de tensiones de interacción compleja, las cuales alcanzan sus espesores específicos, según los diferentes espacios y niveles institucionales y societales que, en cada caso, las caracterizan y definen.

La categoría de 'dispositivo pedagógico' organiza y estructura la interpretación de la institución educativa, en función de la incidencia que, sobre esta, ejercen las determinaciones dominantes de las políticas públicas. Sin embargo, la categoría esboza una concepción que ya no entiende a la institución educativa, como si por naturaleza esta dependiera irrestrictamente de tales determinaciones de poder, el cual comprende "una relación de fuerza en sí mismo." (Foucault, 2000, p. 27). En perspectiva de lo que es pertinente, a propósito del principio de la autonomía de la institución educativa: 
[...] si queremos entender la producción, reproducción y transformación de formas de consciencia y de práctica, necesitamos comprender la base social de una distribución de poder y principios de control determinados que sitúen, resitúen y pongan en oposición formas de consciencia y de práctica. Postulamos que, entre poder y conocimiento y entre conocimiento y formas de consciencia, siempre está el dispositivo pedagógico (DP) (Bernstein, 1997, p. 186).

En tal sentido, justamente, la configuración del dispositivo pedagógico hace ver que en el origen de toda determinación dominante de poder, relacionada con la organización del funcionamiento de la institución educativa, se establece siempre una necesidad insoslayable por dirimir y solventar la presencia, ya previamente determinada de relaciones de fuerza entre las clases sociales involucradas que, para los efectos del proyecto dominante, deben ser adecuadamente controladas y organizadas, en función de los propios propósitos y objetivos que se encuentran implicados en tal proyecto. Es así como, al mismo tiempo, cabe destacar un sistema de reglas distributivas, de recontextualización y de evaluación (Bernstein, 1997, pp. 186-192). "Estas reglas [...] no son independientes de las ideologías. En efecto, las reglas del dispositivo pedagógico participan esencialmente en la divulgación y en la restricción de las formas de consciencia" (Bernstein, 1997, p. 185).

En el dominio del escenario áulico, por ejemplo, quien tiene a su cargo impartir la formación, es alguien que se encuentra inscrito en una dinámica de enseñanza/aprendizaje, la cual le confiere la posibilidad del ejercicio de un margen relativo de autonomía. Es este precisamente el umbral, en donde se configura y articula el escenario de interacciones que permite llevar a cabo la producción del saber docente. Por este motivo, el espacio mismo del aula, en tanto que lugar del proceso de enseñanza/aprendizaje, constituye una entidad que cuenta así con su propia disposición de autonomía relativa.

No obstante, apropiarse de las implicaciones que esto hace intervenir, presupone considerar la configuración de disposiciones apropiadas de subjetividad y de una cultura institucional. Es decir, esta disposiciones deben involucrar una toma de conciencia y la dinamización de una lucidez de sentido prospectivo, que no pueden tener su anclaje apropiado, más que en el lugar de las prácticas académicas y en una disposición de gestión institucional asumidas protagónicamente. Cuando esto acontece, la autonomía relativa adopta una identidad que se releva a sí misma, a partir de una integración dinámica de los diferentes estilos y prácticas de la gestión académica, de la particular apropiación y desarrollo del currículum y del proyecto de formación. 
En el nivel de la educación superior, la autonomía relativa, condicionada por diversos factores e inscrita en un contexto de presiones diversas y complejas, constituye un acontecimiento siempre presente y de implicaciones institucionales irreductibles. Sin embargo, la autonomía también puede llegar a condensarse en la cristalización de un "hábitus" (Bourdieu, 2000, pp. 51-64). o en el acaecimiento de una inercia institucional. En esta situación, la autonomía adopta la condición de un axioma institucionalmente formalizado, sustentador de unas prácticas petrificadas que discurren subrogadas a los códigos fantasmáticos que se atribuyen a alguna mitología fundacional. Es por esto que, en la actualidad, plantearse el significado del principio de la autonomía universitaria implica atender, de manera especial, a "los modos 'políticamente correctos' de pensar, sentir, actuar y relacionarse entre sí" (Remedi, 2003, p. 15). por parte de los actores que integran las comunidades académicas de la educación superior.

Por tanto, ¿qué es lo que permanece diluido en una situación codificada de la manera enunciada? Se diluye la condición de la autonomía relativa entendida y asumida, como práctica académica sustentada en el ejercicio del principio de institucionalidad.

De acuerdo con la perspectiva de las labores que, en el marco del principio de autonomía, las instituciones de educación superior se ven en la necesidad de abordar y llevar a cabo, cabe destacar el enunciado que propone L. Garay, en el sentido de que estas instituciones deben ahora desarrollar esfuerzos por abrir los espacios y las condiciones que les permitan generar "el advenimiento de imaginarios instituyentes como fuente de nuevas simbolizaciones y nuevos sentidos" (Garay, 1996, pp. 155-156).

Así el escenario académico y de formación de una institución de educación superior:

Es también el ámbito donde lo instituido entra en juego con las tendencias, las fuerzas y los fenómenos instituyentes. Configura el lugar donde el individuo puede preguntarse acerca de la eficacia, la verdad, la justicia, la ética de lo establecido; puede cuestionarlo y proponerse su cambio (Fernández, 1998, p. 25).

La naturaleza de una institución educativa no puede ser, en consecuencia, adecuadamente comprendida, si se le considera como una institución capaz de definir y expresar la realización unilateral de un proyecto homogéneo. Es decir, un propósito en donde se manifiesta el establecimiento, sin más, del consenso entre los intereses y expectativas de formación educativa que se juegan entre los diferentes actores y sectores sociales interesados. Esta observación tiene especial importancia, en la medida de que, en la actualidad, se esbozan y circulan enfoques y visiones interesados en promover una 
situación de "consenso societal", como condición preliminar para el logro de lo que, en su lugar, se denomina como el "consenso político" que sería necesario para "alcanzar acuerdos nacionales capaces de atravesar cambios de gobierno y las turbulencias del debate político normal" (Ottone, 1998). Este es con toda claridad, un deseo legítimo y encomiable. No obstante, tampoco puede perderse de vista que, de acuerdo con lo que B. Bernstein denomina el 'campo pedagógico recontextualizador', en el escenario de la educación superior pública, participan "como núcleo posiciones, agentes y prácticas" que proceden desde muy diversos espacios y que son expresión de las posiciones y visiones de muy diversos actores: "departamentos universitarios de educación, facultades de educación, escuelas, junto con los procedentes de fundaciones, medios de comunicación especializados, revistas, semanarios y editoriales" (Bernstein, 1997, p. 203).

La consideración de las disposiciones constitucionales da su sustento institucional a la autonomía universitaria -en el caso de Costa Rica, los artículos 79, 84 y 85 de la Constitución Política, constituyen los basamentos indeclinables, a partir de los cuales, deben desarrollarse cualquier discusión, análisis, puesta en ejercicio y validación de este insoslayable principio. No obstante, tampoco los alcances de su ejercicio pueden reducirse a una contemplación pasiva o reactiva, respecto de las disposiciones y normas que establece el marco constitucional. Esto es necesario de tener en cuenta, en la medida en que, desde dentro de la institución misma, se puede llegar a producir la emergencia de las presiones que abogan por llevar a cabo una minusvalorización u obnubilación de los atributos de institucionalidad que dan su identidad específica y que definen las características de la educación superior pública (Semanario Universidad, № 1626, p. 10).

La debilidad de no contar con una visión fundada en la complejidad y la naturaleza de las exigencias que hoy se le plantea a la educación superior, deviene un impedimento teórico/práctico que obstaculiza la definición de una adecuada organización de los planteamientos y estrategias, sobre los cuales la autonomía podría hacerse valer, como elemento crítico esencial de la identidad de la institución de educación superior. Esto pone en riesgo también la posibilidad de establecer las articulaciones de sentido y de acción programática que les permitan a estas instituciones, establecer su relación con la sociedad, por medio de la criticidad y de la incidencia prospectiva.

Determinar cuáles son los objetivos que deberían perseguir las universidades y el modo como deberían hacerlo, no es sencillamente un proceso de negociación entre el mundo de la política, el gobierno y la sociedad. Es además un proceso en el cual la 
comunidad investigadora debe negociar las nuevas ideas e interpretaciones que genera el trabajo que realiza con esos mismos "socios sociales". (Neave, 2001, p. 28)

A este respecto, podría señalarse que quizá exista alguna razón, al indicar que una institución cuyo proyecto educativo asume como horizonte "la formación de una conciencia creativa, crítica y objetiva" (Consejo Universitario, 2004, p. 1). tenga ella misma que ser crítica por definición y de manera esencial. Tal como lo señala Y. González: "La Universidad, hoy más que nunca, sabe que no puede permanecer al margen del debate y que, como escucha de los distintos planteamientos sociales, forjadora de valores ciudadanos y formadora de opinión, debe sugerir, inspirar y responder" (González, 2005, p. 10). Desde esta perspectiva, en consecuencia, el principio de la autonomía universitaria adquiere su validación y legitimidad, en términos tales como los que se exponen a continuación:

La Universidad tiene que hacer uso de su liderazgo, de su capacidad reflexiva, de sus conocimientos, de su capacidad de diálogo, de su pluralidad como una fuerza para resolver problemas o al menos orientarlos hacia la consecución de objetivos sociales (González, 2005, p. 10).

Esta donación de liderazgo, que se otorga a la institución de educación superior pública, no procede del capricho de sus actores internos, ni mucho menos, es producto de un deseo gratuito. Por el contrario, en ello va implicada la conciencia de la historicidad e identidad institucionales de la educación superior pública, que les asigna a estas instituciones, un lugar y unas funciones específicas en el marco institucional de la sociedad.

Tal como señala B. Bernstein, de lo que se trata, en última instancia, es de analizar la vigencia o no de la autonomía en el contexto, en donde efectivamente es producida, en el lugar o espacios donde despliega su escenario específico y se realiza, según sus específicas condiciones de historicidad y de identidad. 


\section{Conclusiones}

A partir de relevar la condición de la "doble verdad" a que se refieren Bourdieu/Passeron y que, en opinión de estos autores, caracteriza a la educación superior como una de sus disposiciones constitutivas, en la actualidad, valdría decir, los contenidos y sentidos que definen dicha doble verdad, presentan una ineludible y delicada configuración, la cual, en la presente oportunidad, cabe situarla en la imagen de Escila y Caribdis, o bien, en el umbral de riesgo y tensión que, en la obra homérica, se atribuye a estas dos figuras.

Indagar en torno al papel que una institución de educación superior pública hoy se plantea y asume como propio, implica la consideración de sus especificidades académicas e institucionales, así como, por otra parte, el relevamiento de los aspectos críticos que median en la relación que estas instituciones establecen con los distintos actores situados en los contextos históricos, institucionales y societales en los que ellas se encuentran inscritas.

Dicha indagación presupone, por consiguiente, considerar la dimensión del reconocimiento sistemático y permanente de las expectativas y demandas que, de una u otra manera, le formulan los diferentes actores que tienen depositados intereses determinados en su desempeño y en los resultados del proyecto de formación que ella está realizando.

Asimismo, esta noción comporta la consideración y la convicción asumidas de que la institución y su modelo educativo constituyen, como tales, actores igualmente protagónicos que definen su propio lugar y que trazan su trayectoria de participación en el marco de las proyecciones e intereses que caracterizan el comportamiento y las expectativas de tal conjunto de actores.

A tal efecto, en el presente artículo hemos intentado, de una manera analítica y reflexiva, abordar el siguiente argumento: una cuestión es el principio de la autonomía universitaria, en términos de una disposición institucional establecida, y otra es ubicarlo en función de un horizonte siempre abierto de construcción de institucionalidad. Entre un asunto y el otro, la diferencia es sustantiva, aunque no lo es de ningún modo extrínseca. Una dimensión remite a la lógica de lo instituido; la otra conduce a los procesos de lo instituyente. Eventualmente, una puede producir una sacralización contemplativa de lo existente en sí mismo; la otra, en cambio, forma parte inherentemente de toda práctica académica y de gestión que se asuma inscrita en la lógica de la renovación y de la actualización institucional.

Por lo tanto, más allá de los términos que pudiera acopiar una defensa axiomática y prosaica del principio de la autonomía universitaria, los elementos aquí esbozados convergen en la identificación de una heurística que permita asumir el análisis de este principio, a partir fundamentalmente de concebirlo como una instancia o como un dispositivo 
que, por una parte, posibilita a las instituciones de educación superior, definir el proyecto educativo que la sociedad les demanda; por la otra, concita a replantearse el horizonte del proyecto académico institucional, por medio de una interlocución con los requerimientos de formación que, en la actualidad, promueven y demandan actores tan importantes, como lo son las autoridades del Gobierno, los agentes del sector productivo, los organismos multilaterales y las propias familias de los estudiantes.

\section{Referencias}

Allende, Jorge. (2001). El impacto del avance de las ciencias sobre la sociedad en las primeras décadas del siglo XXI. El contexto para la educación. En OREALC (2001). Análisis de prospectivas de la educación en la región de América Latina y el Caribe, Santiago de Chile: OREALC/UNESCO. Recuperado de http://www.unesco.cl/medios/biblioteca/documentos/analisis prospectivas lac esp.pdf

Apple, Michael W. (1989). Profesores y textos. Una economía política de la clase y el origen de las relaciones en la educación. Madrid: Centro de Publicaciones del Ministerio de Educación y Ciencia/Paidós.

Balán, Jorge y García de Fanelli, Ana María. (2002). El sector privado de la educación superior. En Kent, Rollin (comp.) (2002). $2^{\mathrm{a}}$ ed. Los temas críticos de la educación superior en América Latina en los años noventa. Estudios comparativos (pp. 169253). Ciudad de México: Facultad Latinoamericana de Ciencias Sociales, Universidad Autónoma de Aguascalientes, Fondo de Cultura Económica.

Banco Interamericano de Desarrollo-BID. (1997). La educación superior en América Latina y el Caribe. Documento de estrategia, Washington D.C.: BID. Recuperado de http://www.iadb.org/sds/doc/edu\%2D101s.pdf

Barnett, Ronald. (2001). Los límites de la competencia. El conocimiento, la educación superior y la sociedad. Barcelona: Gedisa.

Bernstein, Basil. (1997). La estructura del discurso pedagógico. $3^{a}$ ed. Madrid: Ediciones Morata.

Bernstein, Basil. (1998). Pedagogía, control simbólico e identidad. Teoría, investigación y crítica. La Coruña, Madrid: Fundación Paideia, Ediciones Morata.

Bourdieu, Pierre. (2000). Capital cultural, escuela y espacio social. $3^{a}$ ed. Ciudad de México: Siglo XXI.

Bourdieu, Pierre y Passeron, Jean-Claude. (1998). La reproducción. Elementos para una teoría del sistema de enseñanza, $3^{a}$ ed. Ciudad de México: Distribuciones Fontamara. 
Brunner, José Joaquín. (2002). Educación en América Latina durante la década de 1980: la economía política de los sistemas. $2^{a}$ ed. En Kent, Rollin (comp.). Los temas críticos de la educación superior en América Latina en los años noventa. Estudios comparativos (pp. 106-168). Ciudad de México: Facultad Latinoamericana de Ciencias Sociales/Universidad Autónoma de Aguascalientes, Fondo de Cultura Económica.

Comisión Económica para América Latina y El Caribe. (2000). Equidad, desarrollo y ciudadanía. Versión definitiva. Santiago de Chile: Secretaría Ejecutiva de la CEPAL/UNESCO. http://www.cepal.cl/publicaciones/SecretariaEjecutiva/1/lcg2071/lcg2071.pdf

Conferencia Mundial sobre la Educación Superior. (1998). La educación superior en el siglo XXI: visión y acción. Informe final. París: División de la Enseñanza Superior de la UNESCO.

Didou Aupetit, Sylvie. (2000). Sociedad del conocimiento e internacionalización de la educación superior en México. Ciudad de México: ANUIES.

Fernández, Lidia. (1998). Análisis de lo institucional en la escuela. Un aporte a la formación autogestionaria para el uso de los enfoques institucionales. Notas teóricas. Buenos Aires: Paidós.

Foucault, Michel. (2000). Defender la sociedad. Buenos Aires: Fondo de Cultura Económica.

Garay, Lucía. (1996). La cuestión institucional de la educación y las escuelas. Conceptos y reflexiones. En Butelman, Ida, Pensando las instituciones. Sobre teorías y prácticas en educación. Buenos Aires, Argentina: Paidós.

García Guadilla, Carmen. (1995). Universidad latinoamericana: del "casillero vacío" al escenario socialmente sustentable. En La universidad latinoamericana ante los nuevos escenarios de la región (pp. 41-70). Ciudad de México: UDUAL/Universidad Iberoamericana.

González García, Yamileth. (2002, agosto). Comunicación personal. Ciencia, tecnología y valores. Ponencia presentada en el Foro: Ciencia, Tecnología y Valores. Ministerio de Ciencia y Tecnología, San José de Costa Rica.

González García, Yamileth. (2004a). Equidad de género e inclusión social como tareas inconclusas de la Universidad de Costa Rica. Taller "Una universidad pública comprometida con la equidad de género y con la inclusión social en la investigación y la docencia: avances y desafíos en la Universidad de Costa Rica", Centro de Investigación en Estudios de la Mujer (CIEM). Universidad de Costa Rica.

González García, Yamileth. (2004b). Universidad de Costa Rica: regionalización y ampliación de la cobertura. Mesa Redonda: Regionalización y ampliación de la cobertura, septiembre de 2004, Consejo Universitario, Universidad de Costa Rica, Ciudad Universitaria "Rodrigo Facio". 
González García, Yamileth. (2005). Informe de labores 2004-2005. Publicaciones de la Universidad de Costa Rica, Ciudad Universitaria "Rodrigo Facio", San Pedro de Montes de Oca.

Granja Castro, Josefina (comp.). (2003). Miradas a lo educativo. Exploraciones en los límites. Ciudad de México: Plaza y Valdés.

Hopenhayn, Martin. (2003). Educación, comunicación y cultura en la sociedad de la información: una perspectiva latinoamericana. Santiago de Chile: Revista de la CEPAL Nº 81.

Huertas, Lisbeth (redac.). (2005, 30 de junio). Liberacionistas arremeten contra medios de comunicación. Semanario Universidad, p. 10.

Kent, Rollin. (1995). Puntos para una agenda de políticas de educación superior en América Latina. En La universidad latinoamericana ante los nuevos escenarios de la región (pp. 71-82). Ciudad de México: UDUAL/Universidad Iberoamericana.

Kent, Rollin. (2002). Las políticas de evaluación. En Kent, Rollin (comp.) $2^{\mathrm{a}}$ ed., Los temas críticos de la educación superior en América Latina en los años noventa. Estudios comparativos (pp. 254-324). Ciudad de México: Facultad Latinoamericana de Ciencias Sociales; Universidad Autónoma de Aguascalientes; Fondo de Cultura Económica.

Klein, Lucía y Sampaio, Helena. (2002). Actores, arenas y temas básicos. En Kent, Rollin (comp.), Los temas críticos de la educación superior en América Latina en los años noventa. Estudios comparativos (pp. 31-105). Ciudad de México: Facultad Latinoamericana de Ciencias Sociales, Universidad Autónoma de Aguascalientes, Fondo de Cultura Económica.

Ladrière, Jean. (1977). El reto de la racionalidad. La ciencia y la tecnología frente a las culturas. Salamanca: Ediciones Sígueme.

Lam, Alice. (2002). Los modelos societales alternativos de aprendizaje e innovación en la economía del conocimiento. Revista Internacional de Ciencias Sociales, (171), Publicaciones de la UNESCO, París. Recuperado de http://campusoei.servidorprivado.com/salactsi/lam.pdf\#search='alice\%20lam'

Morin, Edgar. (2001). Los siete saberes necesarios para la educación del futuro. Ciudad de México: Librería El Correo de la UNESCO.

Muñoz Izquierdo, Carlos. (1995). La universidad latinoamericana ante los nuevos escenarios de la región. En La universidad latinoamericana ante los nuevos escenarios de la región (pp. 11-23). Ciudad de México: UDUAL, Universidad Iberoamericana.

Neave, Guy. (2001). Educación superior: historia y política. Estudios comparativos sobre la universidad contemporánea. Barcelona: Gedisa. 
Ottone, Ernesto. (1998). La apuesta educativa en América Latina. Revista de la CEPAL, Número Extraordinario, Santiago de Chile. Recuperado de http://www.cepal.cl/publicaciones/SecretariaEjecutiva/7/lcg2037/ottone.htm.

Popkewitz, Thomas S. (1997). Sociología política de las reformas educativas. EI poder/saber en la enseñanza, la formación del profesorado y la investigación. La Coruña, Madrid: Fundación Paideia, Ediciones Morata.

Proyecto Estado de la Nación en Desarrollo Humano Sostenible. (2003). Estado de la nación en desarrollo humano sostenible: noveno informe 2002. San José, C.R.: Proyecto Estado de la Nación.

Ribeiro Durham, Eunice. (2002). Introducción: los estudios comparativos de la educación superior en América Latina. En Kent, Rollin (comp.) (2002). $2^{\mathrm{a}}$ ed., Los temas críticos de la educación superior en América Latina en los años noventa. Estudios comparativos ( $\mathrm{xx}-\mathrm{xx}$ ). Ciudad de México: Facultad Latinoamericana de Ciencias Sociales/Universidad Autónoma de Aguascalientes/Fondo de Cultura Económica.

Schön, Donald A. (1992). La formación de profesionales reflexivos. Hacia un nuevo diseño de la enseñanza y el aprendizaje en las profesiones. Madrid: Centro de Publicaciones del Ministerio de Educación y Ciencia, Paidós.

Schvarstein, Leonardo. (1995). Psicología social de las organizaciones. Nuevos aportes. Buenos Aires: Paidós.

Secretaría Permanente del CSUCA. (1959). Memoria de las reuniones del Consejo Superior Universitario Centroamericano 1949-1959. León, Nicaragua: Publicaciones de la Secretaría Permanente del CSUCA.

Secretaría Permanente del CSUCA. (1996). Misión CSUCA XXI. Documento central del IV Congreso Universitario Centroamericano. San José: EDUCA.

Thompson, Grahame. (1999). Introducción: situar la globalización. Revista Internacional de Ciencias Sociales, (160). Disponible http://www.unesco.org/issj/rics160/titlepage160.html

Torres, Jurjo. (2000). Globalización e interdisciplinariedad: el currículum integrado. $4^{\mathrm{a}}$ ed. Madrid: Ediciones Morata.

Tünnermann Bernheim, Carlos. (1997). Hacia una nueva educación superior. Caracas: Ediciones CRESALC/UNESCO.

UNESCO. (1996). Declaración Mundial sobre Educación para Todos. Básica, Año III, julio/agosto de 1996, No 12. Ciudad de México: Patronato SNTE para la Cultura del Maestro Mexicano A.C. 